\title{
The facets of an impostor - development and validation of the impostor-profile (IPP31) for measuring impostor phenomenon
}

\author{
Fabio Ibrahim ${ }^{1}$ (D) Johann-Christoph Münscher ${ }^{1}$ (D) $\cdot$ Philipp Yorck Herzberg $^{1}$ (D)
}

Published online: 9 July 2020

(C) The Author(s) 2020

\begin{abstract}
The Impostor Phenomenon (IP) is a characteristic, which is composed of cognitions of inauthenticity, in conjunction with fear of failure, as well as fear of being exposed as a fraud. The IP was first described by Clance (1985), who also developed an accompanying questionnaire. However, this questionnaire left room for optimization (item content, pysychometric properties, and the representing IP as a multidimensional construct). Therefore, we developed an item pool of 450 new items based on the theoretical foundation. The core element characteristics are measured using the theoretically derived scales: Competence Doubt, Working Style, Alienation, Other-Self Divergence, Frugality and Need for Sympathy. Based on a German sample $(N=771,51 \%$ female), aged 18 to 70 years, exploratory and confirmatory factor analysis resulted in a selection of 31 items. The six scales show satisfactory internal consistencies between .69 and .92. Initial construct validity showed positive correlations with convergent (Neuroticism) and discriminant measures (Self-Esteem). The Impostor-Profile (IPP31) is a theoretically founded multidimensional german questionnaire that can be applied in research and practice.
\end{abstract}

Keywords Big five $\cdot$ Clance impostor phenomenon scale $\cdot$ Impostor-profile $\cdot$ Impostor syndrome $\cdot$ Impostor phenomenon $\cdot$ IPP 31

I feel like an impostor when we did that show in Portland. When I was about to get on stage and it was a $[\ldots]$ sold-out arena. I still feel like an impostor. This is so crazy, feels fake. It's just because I have a very high standard and I work really hard and I'm never satisfied.

(The Joe Rogan Experience 2019)

The perceptions described by the comedian Joe Rogan are prototypical for the Impostor Phenomenon (IP). It is characterized by an experience of intellectual or occupational fraudulence (Matthews and Clance 1985) and was first described

Electronic supplementary material The online version of this article (https://doi.org/10.1007/s12144-020-00895-x) contains supplementary material, which is available to authorized users.

Fabio Ibrahim

Fabio.Ibrahim@t-online.de

Johann-Christoph Münscher

j.muenscher@hsu-hh.de

Philipp Yorck Herzberg

herzberg@hsu-hh.de

1 Department of Personality Psychology and Psychological Assessment, Helmut-Schmidt-Universität, Hamburg, Germany by Clance and Imes (1978). The two psychotherapists and professors observed that many of their female clients, despite their qualifications, their awards, or their achievements, did not develop a self-referential sense of success (Clance and O'Toole 1988). Patients could not internalize their successes and felt as if they had illegally obtained their current position through either excessive effort or luck (Matthews and Clance 1985). In consequence, this self-image led to a fear of being exposed. The IP can be described as a dysfunctional personality style (Rohrmann et al. 2016) with negative effects in the working context as well as in private life. Due to the positive correlation of the IP with self-discipline and perceived competence (Bernard et al. 2002), high expressions in the IP has a negative influence on professional achievement and is considered as a performance inhibiting construct (Chae et al. 1995). Convergent validity was shown by the connection with instruments measuring psychological stress experience, higher depressive symptoms, higher self-monitoring and perfectionism (Henning et al. 1998; Thompson et al. 2000; Ferrari and Thompson 2006; Hutchins 2015; Rohrmann et al. 2016). The IP goes along with detrimental consequences such as greater inclinations to depression, lower mental health, and an increased experience of stress (Sakulku and Alexander 2011). Clance and Imes (1978) proposed the psychological construct under the term Impostor Syndrome. Even though 
this term is used in large parts by the scientific community, the authors explicitly pointed out, that the object of investigation is a personality characteristic without clinical implication.

Initially, results indicated that women were predominantly affected by the IP (Clance and Imes 1978). Further investigations revealed, however, that there were no gender differences regarding impostorism (Lester and Moderski 1995; Rohrmann et al. 2016; Leach et al. 2019).

Persons suffering from the IP tend to self-handicapping, fend off praise and have the feeling of stacking up, which leads to the fear of being exposed (Want and Kleitman 2006; Kumar and Jagacinski 2006). Similarities have been found between the depressive attributional style and the IP. Brauer and Wolf (2016) found a negative relation between the internal-stable-global attribution in positive situations and a reversed relation in negative situations. In addition, they found that this detrimental attributional pattern regarding performance was stronger related to the IP than to social situations. These results correspond to previous findings, which show that Impostors are more concerned about mistakes, overestimate the number of mistakes made, and are less satisfied with their performance (Thompson et al. 1998). Moreover, Impostors show lower organizational citizenship behavior and job satisfaction (Vergauwe et al. 2015). Leaders, in particular, are affected frequently by the IP. Rohrmann et al. (2016) found that more than half of the managers surveyed in their sample showed impostor inclinations. Additionally, heads of marketing departments (Fried-Buchalter 1997), people in the founding scene (Sightler and Wilson 2001), and medical specialists (Henning et al. 1998) showed signs of the IP. Furthermore, the IP is more prevalent when a person is starting a new position (Sanford et al. 2015; Parkman 2016). The presence of this phenomenon is not limited to western culture, but also affects persons of collectivist societies in Korea (Chae et al. 1995) as well as in Japan (Fujie 2010). The prevalence of people who have suffered from the feeling of being a fraud at some point in their career was found to be 70\% (Gravois 2007; Badawy et al. 2017). So a differentiated and specific assessment of the phenomenon is, therefore, a relevant research and practical assessment concern.

\section{Measurement of the Impostor Phenomenon}

To measure the IP manifestation, usually, one of the four instruments is used. The first questionnaire was the Harvey Impostor Phenomenon Scale (HIPS; Harvey 1981) which contains 14 items and has an internal consistency of .70 (Hellman and Caselman 2004). Factor analytical investigations indicated a two-factor model (Edwards et al. 1987; Hellman and Caselman 2004). The Perceived Fraudulence Scale (PFS; Kolligian and Sternberg 1991) is a 51-item instrument measuring IP and the reported correlation of the PFS and HIPS is .83. The PFS also correlates positive with the Clance Impostor Phenomenon Scale (CIPS; Clance 1985) and shows instable internal consistencies. The most recent developed instrument is the Leary Impostor Scale (LIS; Leary et al. 2000), which includes seven items and has a reported alpha of .87. The correlation of the Leary Impostor Scale with the existing instruments HIPS, PFS and CIPS range from .70 to .80 (Leary et al. 2000).

However, the most frequently used instrument for measuring Impostor tendencies in the general population is the CIPS (Clance 1985; Holmes et al. 1993; Mak et al. 2019). The instrument is economic with 20 items and allows the categorization of the Impostor score into a light, medium, and strong expression by forming a total score. The internal consistency is high across multiple studies ( $\alpha=.84-.96$; Prince 1989; Holmes et al. 1993; see also Mak et al. 2019). The factor structure of the instrument was tested utilizing exploratory factor analysis (EFA) and confirmatory factor analysis (CFA). Chrisman et al. (1995) and Brauer and Wolf (2016) both found, that a 3-factor solution had the best model fit. The factors Fake, Luck and Discount could be extracted in both the English and German version of the CIPS (Brauer and Wolf 2016; Chrisman et al. 1995). However, using CFA, French et al. (2008(French et al. 2008)), as well as Fujie (2010), have identified a 2-factor model as the most fitting. Jöstl et al. (2012), as well as Simon and Choi (2018), found a unidimensional factor structure to be the most appropriate for the underlying structure.

Nevertheless, there are several caveats in using the CIPS. First, there are optimization possibilities due to the item formulation, which technically consists of several components. The items 5, 9 and 13 contain the quantifier "sometimes", which can lead to confusion in combination with the central answer option "sometimes" from the 5-point Likert scale. Secondly, Mak et al. (2019) noted that the CIPS, PFS, and HIPS are based on the multidimensional construct of the IP, but do not measure subscale characteristics. Instead, they provide total scores that do not allow to differentiate between narrow aspects of the IP — despite evidence of the factor analytical investigation, which shows multidimensionality (e.g., Brauer and Wolf 2016; Chrisman et al. 1995) and, however, is not taken into account regarding the use of the questionnaire. Thirdly, the factor solutions proposed in previous studies show that (a) the item-factor assignment is highly imbalanced; for example, Brauer and Wolf (2016) showed that Discount and Luck consist of only four items and (b) that there are no differential relationships between the scales and external criteria (e.g., measures of self-esteem, fear of negative evaluation, or depressiveness). We argue that a measure to distinguish between the core characteristics of the IP is needed in research and practical applications (e.g., testing outcomes of intervention studies). 


\section{Aim of the Study}

In line with recommendations to clarify the dimensionality of the IP (e.g., Mak et al. 2019), a current, validated measuring instrument for the IP, which maps different elements of the construct through subscales, would allow for a more differentiated assessment. This psychometric gain could lead to a more nuanced interpretation and intervention. This investigation aims to develop a questionnaire for the IP, which on the one hand assesses the core elements of the construct (Clance and O'Toole 1988) through theoretically appropriate items and to make different element-characteristics measurable utilizing subscales.

\section{Item Construction and Preliminary Analysis}

For item construction, theories and descriptions of the IP by Clance (1985), Clance and Imes (1978), Harvey and Katz (1985), as well as Sakulku and Alexander (2011) were analyzed. Emotions, cognitive patterns, and behavioral strategies were isolated and grouped into five categories: Idealistic Ambition, Sorrow-System, Ingratiation, Belief in Incompetence and Inauthenticity. For each, 90 items expressing core concepts were created by three experts, resulting in an initial item pool of 450 item candidates.

A Visual Analogue Scale (VAS; Kuhlmann et al. 2017) ranging from $0 \%$ ("does not apply in any aspect") to $100 \%$ ("applies completely") was selected as the response scale for the Impostor-Profile, as this allows a more nuanced setting specification and increases the information content (Reips and Funke 2008). In a pilot study, 162 items have been selected based on precision as well as simplicity and administered to a German sample of $N=303$ (36.3\% female) with an average age of 23.7 years $(S D=5.8)$. Then, these items were analyzed using factor analysis $(N=303$, ordinary-least-squares extraction, Promax rotation, iteratively excluding items with main loadings $<|.40|$ ). A 7 -factor solution was found, reducing the pool to 65 items. Before starting the validation process the seventh scale of the instrument was excluded after another round of experts concluded that the overall contribution of the scale is negligible (low explained variance $(2.68 \%)$ and the scale containing three items with highly similar content.).

The objectives of this study were: (a) finding an adequate factor solution (item selection criteria: number of items per factor at least three, main loading $>.50$, a difference between main and secondary loading $>.20$ ) with a satisfying model fit $(\mathrm{GFI}>.90 ;$ AGFI > .90; CFI > .90; RMSEA < .08; Hu and Bentler 1999); (b) the construction of scales with sufficient reliability (internal consistency $>.70$ ) and to (c) examine construct validity by investigating the relationships between convergent and divergent instruments.

\section{Method}

\section{Participants and Procedure}

Participants were $N=771$ (391 female; $M=39.5 ; M d=40.0$; $S D=14.0$ ) between 18 and 70 years old persons from Germany who were partly generated by the commercial online survey panel "Consumerfieldwork GmbH" in the period from January to April 2019. Besides demographic data, the survey also asked about occupation and educational level. For crossvalidation purpose, the total sample was randomly split into two subsamples $\left(n_{1}=300, n_{2}=471\right)$. The gender ratio of the sample ( $51 \%$ female) was balanced, with the age distribution being left-handed, with a disproportionate frequency of persons being 18 to 23 -year-olds. Within the occupational groups, pensioners and the unemployed in particular were underrepresented. Employees (58\%) and soldiers (15\%) were well represented. The sample holds a large proportion of people with a school-leaving certificate $(27 \%)$ or vocational training $(35 \%)$. The research data is archived and can be accessed under the Open Science Framework link osf.io/IPP31 (Table 1).

\section{Measures}

Besides the item pool of the Impostor-Profile (65 items), a selection of instruments measuring theoretically related constructs was administered. The Big Five Inventory (BFI; Rammstedt and Danner 2016) in the adaption according to Rammstedt (1997) measures the Big Five.

The questionnaire contains 45 items with a 5-point Likert scale $(1=$ "strongly disagree; $5=$ "strongly agree") to assess the five dimensions Neuroticism, Extraversion, Openness to new Experiences, Conscientiousness, and Agreeableness with a total of 10 facets. The internal consistency ranges from .78 to .83 (Rammstedt and Danner 2016). The construct validity was shown by the connection to the established personality instruments NEO-PI-R and NEO-FFI (Rammstedt and Danner 2016).

The Clance Impostor Phenomenon Scale (CIPS; Clance and O'Toole 1988) contains 20 items and the total score informs about the respondent's impostor tendencies. The instrument has a 5-point Likert scale ( 1 = "not at all true"; 5 = "very true") and the GCIPS, which is the german translation of the questionnaire, shows good psychometrical properties and has an alpha of .88 (Brauer and Wolf 2016).

The Rosenberg Self-Esteem Scale (RSES; Rosenberg 1965) in the adaption of von Collani and Herzberg (2003) contains ten items with a 4-point Likert scale $(1=$ "not true at all"; 4 = "is entirely true") and assesses the two primary factors Self-Diminishing and Positive Self-Esteem. The internal consistency is .84 (von Collani and Herzberg 2003). 
Table 1 Sample description by age, occupation and educational level

\begin{tabular}{|c|c|c|c|c|}
\hline & $\begin{array}{l}\text { Male (\%) } \\
380(49)\end{array}$ & $\begin{array}{l}\text { Female (\%) } \\
391(51)\end{array}$ & Sum $\%$ & \\
\hline \multirow[t]{8}{*}{ Age } & $18-23$ & $92(12)$ & $73(9)$ & 21 \\
\hline & $24-29$ & $53(7)$ & $25(3)$ & 10 \\
\hline & $30-35$ & $24(3)$ & $52(7)$ & 10 \\
\hline & $36-41$ & $37(5)$ & $52(7)$ & 12 \\
\hline & $42-47$ & $38(5)$ & $53(7)$ & 12 \\
\hline & $48-53$ & $48(6)$ & $60(8)$ & 14 \\
\hline & $54-59$ & $60(8)$ & $53(7)$ & 15 \\
\hline & $60-70$ & $28(4)$ & $23(3)$ & 7 \\
\hline \multirow[t]{9}{*}{ Occupation } & Pupil & $0(0)$ & $1(<1)$ & $<1$ \\
\hline & Student & $60(8)$ & $61(8)$ & 16 \\
\hline & Pensioner & $0(0)$ & $1(<1)$ & $<1$ \\
\hline & Unemployed & $0(0)$ & $0(0)$ & 0 \\
\hline & Clerical worker & $200(26)$ & $245(32)$ & 58 \\
\hline & Self-employed person & $27(4)$ & $37(5)$ & 9 \\
\hline & Civil servant & $14(2)$ & $9(1)$ & 3 \\
\hline & Teaching/ Research & $3(<1)$ & $0(0)$ & $<1$ \\
\hline & Soldier & $76(10)$ & $37(5)$ & 15 \\
\hline \multirow[t]{7}{*}{ Education level } & No educational attainment & $1(<1)$ & $0(0)$ & $<1$ \\
\hline & Certificate of secondary Education & $12(2)$ & $11(1)$ & 3 \\
\hline & Secondary school level I certificate & $33(4)$ & $39(5)$ & 9 \\
\hline & School leaving examination & $119(15)$ & $94(12)$ & 27 \\
\hline & Vocational education & $122(16)$ & $149(19)$ & 35 \\
\hline & Master craftsmen/ Technician & $14(2)$ & $11(1)$ & 3 \\
\hline & Bachelor, master or higher & $79(10)$ & $87(11)$ & 21 \\
\hline
\end{tabular}

The persentages have been rounded to whole numbers; the german sample was recruited in the period from January to April 2019

\section{Results}

\section{Step 1: Exploratory Factor Analysis}

Exploratory factor analysis (EFA) was performed using the R-package psych (Revelle and Revelle 2015) on Subsample $1 \quad\left(n_{1}=300\right.$, excellent sampling adequacy, $\mathrm{KMO}=0.93$ ). Principal-axis extraction and Promaxrotation were used and items with a main loading $<|.50|$ or with a difference between main and second loading < |.20| were dismissed. Parallel analysis (Horn 1965) suggested the extraction of seven factors; matching the result in the pre-test however, a six-factor solution proved to be stable. The final item selection comprises 31 items loading on six factors (six Eigenvalues $>1,[1.16-9.70]$; $56 \%$ explained variance), with adequate fit $(\mathrm{RMSR}=.03$; RMSEA $=.058,90 \%$ CI [.048-.062], Tucker-LewisIndex $\left.=.908 ; \chi_{300}^{2}=560.92, p<.01\right)$. Each factor consists of 3-11 items; absolute factor correlations ranged from -.02 to $.66(M=.27, S D=.22)$.

\section{The Impostor-Profile}

The result of the factor-analytical iterations was a questionnaire with a total of 31 items which formed six factors. The six extracted factors reflect core elements as well as concise characteristics of the IP. Table 2 shows the relevant psychometric properties of the items and their factor affiliation. The factors were Competence Doubt, Working Style, Alienation, OtherSelf Divergence, Frugality, and Need for Sympathy. The internal consistency of the six scales indicated by the standardized Cronbach's alpha lay between .69 and .92. Due to the low number of items per IPP31 scale, McDonald's omega is used as a further reliability estimator (Ziegler et al. 2014). The total omega of the scales lie between $\omega_{\mathrm{t}}=.94$ and $\omega_{\mathrm{t}}=.72$.

The scale Competence Doubts (e.g., "Despite former successes, I have strong fear of failure."; $\lambda=.83 ; \omega_{\mathrm{t}}=.94$ ) measures a person's competence-related self-doubt, especially before a performance task. It also measures fear of failure and maladaptive perfectionism. The cause of this self-concept is the external attribution style of positive work results. Besides 
Table 2 Descriptive statistics, internal consistencies, item-total correlations $\left(\mathrm{r}_{\mathrm{it}}\right)$, and factor loadings

\begin{tabular}{|c|c|c|c|c|c|c|c|}
\hline Item & $M(S D)$ & $\alpha^{a}$ & $r_{\text {it }}$ & $\lambda$ & $\begin{array}{l}\text { Skewness/ } \\
\text { Kurtosis }\end{array}$ & Mdn & element $^{\mathrm{b}}$ \\
\hline & Competence Doubt & 0.92 & & & & & \\
\hline 1 & $37.34(30.6)$ & .91 & .81 & .83 & $.46 /-1.09$ & 30 & $\begin{array}{l}\text { Fear of Failure Maladaptive } \\
\text { Perfectionism Self-Doubt }\end{array}$ \\
\hline 2 & 35.23 (27.98) & .91 & .78 & .69 & $.52 /-.9$ & 29 & \\
\hline 3 & $48.4(33.27)$ & .93 & .54 & .63 & $.07 /-1.38$ & 49 & \\
\hline 4 & 27.7 (28.16) & .91 & .76 & .63 & $.98 /-.24$ & 17 & \\
\hline 5 & $26.87(26.26)$ & .92 & .73 & .69 & $.96 /-.18$ & 17 & \\
\hline $6^{r}$ & $39.66(30.69)$ & .93 & .52 & .73 & $.41 /-1.09$ & 34 & \\
\hline 7 & $30.31(28.55)$ & .92 & .67 & .61 & $.83 /-.51$ & 20 & \\
\hline 8 & $31.87(27.06)$ & .92 & .70 & .59 & $.69 /-.58$ & 24 & \\
\hline 9 & 39.33 (29.97) & .91 & .77 & .86 & $.32 /-1.15$ & 35 & \\
\hline 10 & $27.77(27.13)$ & .92 & .69 & .69 & $.98 /-.10$ & 18 & \\
\hline \multirow[t]{2}{*}{11} & $33.40(28.55)$ & .92 & .72 & .54 & $.63 /-.74$ & 25 & \\
\hline & Working Style & .86 & & & & & \\
\hline 12 & $35.8(29.18)$ & .82 & .77 & .75 & $.50 /-.98$ & 30 & Impostor-Cycle Pro- / Precrastination \\
\hline 13 & $41.42(29.84)$ & .82 & .80 & .86 & $.23 /-1.18$ & 40 & \\
\hline $14^{\mathrm{r}}$ & $58.9(29.08)$ & .88 & .40 & .51 & $.29 /-1.07$ & 60 & \\
\hline 15 & $36.34(30.95)$ & .82 & .75 & .78 & $.50 /-1.04$ & 29 & \\
\hline 16 & $40.91(29.12)$ & .83 & .70 & .71 & $.33 /-1.05$ & 38 & \\
\hline \multirow[t]{2}{*}{$17^{\mathrm{r}}$} & $38.04(27.78)$ & .86 & .54 & .56 & $.48 /-.85$ & 34 & \\
\hline & Alienation & .85 & & & & & \\
\hline 18 & $22.58(22.13)$ & .79 & .91 & .81 & $1.13 / .58$ & 15 & Impression-Management \\
\hline 19 & $31.73(27.16)$ & .82 & .74 & .82 & $.66 /-.63$ & 25 & \\
\hline \multirow[t]{2}{*}{20} & $26.07(25.73)$ & .77 & .84 & .70 & $1.02 / .07$ & 17 & \\
\hline & Other-Self Divergence & .79 & & & & & \\
\hline 21 & $30.45(22.87)$ & .74 & .67 & .54 & $.76 / .07$ & 26 & Denial of Competence \\
\hline 22 & $26.14(22.51)$ & .77 & .52 & .78 & $.90 / .18$ & 21 & \\
\hline 23 & $24.08(21.85)$ & .68 & .99 & .91 & $1.13 / .68$ & 17 & \\
\hline \multirow[t]{2}{*}{24} & $32.50(25.28)$ & .77 & .66 & .64 & $.59 /-.49$ & 29 & \\
\hline & Frugality & .71 & & & & & \\
\hline $25^{\mathrm{r}}$ & $49.70(28.54)$ & .62 & .55 & .65 & $.51 /-.79$ & 50 & Fear and Guilt about Success \\
\hline $26^{\mathrm{r}}$ & $64.92(27.92)$ & .64 & .51 & .45 & $.05 /-.96$ & 70 & \\
\hline $27^{\mathrm{r}}$ & $52.05(25.67)$ & .62 & .57 & .58 & $.08 /-.71$ & 51 & \\
\hline \multirow[t]{2}{*}{28} & $40.64(34.89)$ & .73 & .40 & .45 & $.40 /-1.32$ & 31 & \\
\hline & Need for Sympathy & .68 & & & & & \\
\hline 29 & $60.25(26.92)$ & .40 & .62 & .76 & $.43 / .6$ & 62 & Superwoman/-man Aspects \\
\hline 30 & $54.84(25.77)$ & .46 & .59 & .68 & $.29 / .6$ & 56 & \\
\hline 31 & $72.51(21.26)$ & .79 & .31 & .53 & $.85 / .46$ & 77 & \\
\hline
\end{tabular}

The median value is shown in italics and the standard deviation in brackets; ${ }^{\text {a }}$ Standardized Cronbach's alpha; total values for subscales; corrected values when the item is dropped for each item; ${ }^{\mathrm{b}}$ underlying theoretical assumptions for the items in accordance with Sakulku and Alexander 2011; we used the german version of the IPP31

the negative consequences for subjective well-being, such as anxiety and depression, a high degree in this factor also indicates a reduced professional ambition. Working Style (e.g., "Often I postpone starting important tasks."; $\lambda=.86$; $\left.\omega_{\mathrm{t}}=.89\right)$ is defined as a scale that measures the extent to which a person is prone to procrastination. A high score in Working
Style indicates procrastination tendencies, while a low score indicates precrastination tendencies. Both working styles are regarded as different compensation attempts concerning the fear of failure due to a performance task. In both cases, the positive work result is attributed externally to the overly early work start or the last possible excessive workload. Both 
working styles are typical for impostorism but can be differentiated by scale expression. The scale Alienation (e.g., "I often feel like I hold back my real personality. "; $\lambda=.82$; $\left.\omega_{\mathrm{t}}=.86\right)$ is specified as a scale which describes the missing feeling of authenticity and the high expression of impression management. High expression in this factor is due to the feeling of not being sufficient, so tendencies of self-control also reach into private life. Other-Self Divergence (e.g., "People overestimate me."; $\left.\lambda=.93 ; \omega_{\mathrm{t}}=.82\right)$ measures the extent to which the expectations of the environment are perceived as overstraining. The cause of this perceptional distortion is a large delta between the low self-efficacy expectation and the successful work perceived by others. The large difference between self- and other image intensifies the pressure to adapt as well as the feeling of not being adequate. The fifth scale Frugality (e.g., "It is very important to me to create something significant"; $\lambda=-.65 ; \omega_{\mathrm{t}}=.82$ ) describes the person's tendency to low self-expectations and unwillingness to lead. The fear of responsibility and challenges results from the fear of being exposed as an impostor. This reluctance inhibits career advancement and personal development. Need for Sympathy (e.g., "I think it is important to appear sympathetic."; $\lambda=.76 ; \omega_{t}=.72$ ) measures the need for popularity and goodwill on the part of others. A high level on this scale indicates that the person believes in being dependent on the goodwill of others. Too much tolerance, however, has professional disadvantages and also serves as an external object of success attribution.

\section{Confirmatory Factor Analysis}

The 6-factor model was validated using the data of Sample 2 $\left(n_{2}=471\right)$ through confirmatory factor analysis (CFA); calculations were performed using the R-package lavaan (Rosseel et al. 2017). Robust maximum-likelihood (MLR) estimation was used as recommended by Rhemtulla et al. (2012). As expected, the $\chi^{2}$-test was statistically significant $\left(\chi_{419}^{2}=\right.$ $1040.3, p<.001)$. The inspection of goodness-of-fit indicated good model-data fit $(\mathrm{GFI}=.852$; $\mathrm{AGFI}=.825$; RMSEA $=.063,90 \%$ CI [.056-.065]; CFI = .910). The loadings were high for each factor $(\geq .40$; see Table 2$)$.

\section{Psychometric Properties}

Next, we examined the item- and scale properties of the IPP31 (Table 2). The item difficulties showed a balanced pattern ranging between $M_{\min }=22.6$ and $M_{\max }=72.5$ across the scales with standard deviations between 21.3 and 34.9 The corrected itemtotal correlation was satisfying and indicated to discriminate well $\left(.31 \leq r_{\text {it }} \leq .99\right)$. The analysis of skewness and kurtosis indicated no deviations from normality. We tested the reliability by internal consistency analysis and found good alpha coefficients for all scales $(\alpha \geq .79)$ except for Frugality $(\alpha=.71)$ and Need for
Sympathy $(\alpha=.68)$ considering the low number of items per scale and the items' good discrimination power, we decided to retain the scales. In addition, the reliability estimator McDonald's omega, which is more suitable for scales with a small number of items (Revelle and Zinbarg 2009), shows sufficient reliability $\omega_{\mathrm{t}}=.94$ and $\omega_{\mathrm{t}}=.72$. The intercorrelation of the scales ranged from $r=-.20$ to $r=.65$ (Table 3). In particular, the Competence Doubt scale correlates positive with Alienation $(r=.61)$ and Other-Self Divergence $(r=.65)$. The scale Frugality shows the highest association with the scale Other-Self Divergence $(r=.05)$.

\section{Nomological Validity}

To study the nomological validity, we examined the relationships between the IPP31 scales and positive associated (CIPS; Neuroticism) as well as negative associated (Conscientiousness, Extraversion, Self-Esteem) traits. We used the total sample of $N=771$ persons to investigate the validity correlations. To check the measuring intention of the IPP31 the anticipated relation was: $\mathrm{H} 2 \mathrm{a}$ ) a positive correlation between the scale Competence Doubt and the CIPS.

The existing research results on CIPS and the Big 5 dimensions (Bernard et al. 2002; Chae et al. 1995; Ross et al. 2001; Vergauwe et al. 2015) led to the following hypotheses that: H2b) Neuroticism shows a positive correlation with the Competence Doubt scale; H2c) Extraversion shows a negative correlation with Competence Doubt, a negative correlation with Alienation and a negative correlation with Other-SelfDivergence; H2d) Conscientiousness has a negative correlation with Working Style; H2e) Openness has no connection to Competence Doubt; $\mathrm{H} 2 \mathrm{f}$ ) Agreeableness shows a positive connection to Competence Doubt and shows a positive correlation with Frugality and Need for Sympathy. The research results of Schubert and Bowker (2017), who found a negative correlation between self-esteem and CIPS, led to the hypothesis that H2g) SelfEsteem shows a negative correlation with Competence Doubt, Alienation, and Other-Self Divergence.

The BFI showed the expected correlations with the scales of the IPP31 (Table 3). Neuroticism showed robust correlations with Competence Doubt $(r=.68)$ so that the assumption H2b) can be accepted. Besides Neuroticism showed a significant correlation with Working Style $(r=.25)$, Other-Self Divergence $(r=.38)$ and Alienation $(r=.46)$. The scale Extraversion showed negative correlations, especially with the scale Alienation $(r=-.49)$, Other-Self Divergence $(r=$ -.25) and Competence Doubt $(r=-.39)$. The anticipated correlation between Extraversion and Competence Doubt could be found, so H2c) can be verified. Conscientiousness showed a negative correlations with Working Style $(r=-.71)$ and leads to the acceptance of $\mathrm{H} 2 \mathrm{~d}$ ). Moreover Conscientiousness showed a negative correlation with Competence Doubt $(r=$ 
Table 3 Correlations of the IPP31 subscales and the Big-Five Inventory (BFI), Clance Impostor Phenomenon Scale (CIPS), and Rosenberg Self-esteem Scale (RSES)

\begin{tabular}{|c|c|c|c|c|c|c|c|}
\hline & \multirow[t]{2}{*}{ Subscale $(\alpha)$} & \multicolumn{6}{|c|}{ IPP $31^{\mathrm{a}}$} \\
\hline & & $\mathrm{CD}$ & WS & A & O-S D & $\mathrm{F}$ & NfS \\
\hline \multirow[t]{6}{*}{ IPP31 } & $\mathrm{CD}$ & 1 & .38 & .61 & .65 & -.04 & .26 \\
\hline & WS & & 1 & .32 & .31 & -.04 & .07 \\
\hline & $\mathrm{A}$ & & & 1 & .52 & -.03 & .16 \\
\hline & O-S D & & & & 1 & -.05 & .21 \\
\hline & $\mathrm{F}$ & & & & & 1 & -.20 \\
\hline & NfS & & & & & & 1 \\
\hline \multirow[t]{15}{*}{ BFI } & Neuroticism (.72) & .68 & .25 & .46 & .38 & .14 & .11 \\
\hline & Anxiety (.74) & .65 & .22 & .38 & .36 & .18 & .16 \\
\hline & Depression $(.70)$ & .58 & .25 & .48 & .36 & .06 & .04 \\
\hline & Extraversion (.93) & -.39 & -.17 & -.49 & -.25 & -.32 & .08 \\
\hline & Assertiveness (.91) & -.37 & -.12 & -.39 & -.23 & -.27 & .02 \\
\hline & Activity $(.77)$ & -.34 & -.29 & -.33 & -.25 & -.37 & .15 \\
\hline & Openness (.81) & -.11 & -.04 & -.09 & -.16 & -.26 & .15 \\
\hline & Openess for aesthetics $(.82)$ & -.03 & .03 & -.04 & -.10 & -.12 & .12 \\
\hline & Openess for ideas (69) & -.11 & -.07 & -.07 & -.13 & -.28 & .14 \\
\hline & Conscientiousness (.88) & -.37 & -.71 & -.29 & -.33 & -.05 & .04 \\
\hline & Orderliness $(.83)$ & -.30 & -.56 & -.24 & -.24 & $<.01$ & -.04 \\
\hline & Self-discipline (83) & -.38 & -.70 & -.28 & -.33 & -.08 & .04 \\
\hline & Agreeableness (.74) & -.04 & .05 & -.05 & -.02 & -.21 & .21 \\
\hline & Altruism (.71) & .04 & .04 & -.07 & .02 & -.15 & .30 \\
\hline & Conformity $(.70)$ & -.09 & -.05 & -.08 & -.07 & -.17 & .10 \\
\hline \multirow[t]{4}{*}{ CIPS } & CIPS-Score & .80 & .38 & .54 & .59 & -.04 & .19 \\
\hline & Luck (.69) & .51 & .26 & .36 & .44 & .01 & .09 \\
\hline & Fake (.84) & .79 & .33 & .50 & .52 & -.07 & .18 \\
\hline & Discount (.73) & .63 & .22 & .43 & .46 & .06 & .13 \\
\hline \multirow[t]{4}{*}{ RSES } & Global self-worth (.83) & -.74 & -.30 & -.53 & -.48 & -.08 & -.07 \\
\hline & Positive self-worth self-satisfaction (.93) & -.43 & -.17 & -.30 & -.32 & -.12 & .07 \\
\hline & Positive self-worth self-efficacy (.77) & -.57 & -.23 & -.44 & -.34 & -.08 & -.04 \\
\hline & Negative self-worth (.83) & .70 & .30 & .49 & .45 & .03 & .11 \\
\hline
\end{tabular}

a Abbreviated IPP31 dimensions: (CD) Competence Doubt, (WS) Working Style, (A) Alienation, (O-S D) OtherSelf Divergence, (F) Frugality and (NfS) Need for Sympathy; correlations greater |.25| are highlighted in boldface; $|r|>.07 / .10 / .13$ are related to $p<.05 / .01 / .001$
-.37), Other-Self Divergence $(r=-.33)$ and Alienation $(r=$ -.29). The BFI scale Openness showed as expected no correlation to Competence Doubt (H2e)). Interestingly Openness has a negative association with Frugality $(r=-.26)$. The hypothesized positive correlation of Agreeableness with Competence Doubt ( $r=-.04)$ and also the anticipated positive correlation of Agreeableness to Frugality $(r=-.21)$ has to be rejected (H2f)). The last presumed negative correlation between Self-Esteem and the IPP31 scale Competence Doubt $(\mathrm{H} 2 \mathrm{~g}))$ could be accepted $(r=-.74)$.

\section{Analyses of Age and Gender}

The investigation of the relationships between age and the IPP31 scales shows that age represents a predictor for IP tendencies. Significant correlations between age and Competence Doubt $(r=-.21)$, Working-Style $(r=-.28)$, Other-Self Divergence $(\mathrm{r}=-.14)$ and Frugality $(\mathrm{r}=.38)$ could be found. In addition, a significant positive link between the female gender and the IPP scales Competence Doubt $(r=.22)$, frugality $(r=.14)$ and Need for Sympathy $(r=.18)$ could be found. The CIPS-Score also shows a significant positive association with the female gender $(r=.16)$.

\section{Discussion}

This study introduced the IPP31 and described the construction and validation of a current multidimensional instrument for the assessment of the IP. A print version, 
as well as a link to an interactive online version of the questionnaire, can be found in the online Ressource 1 . The theoretical basis for item generation was derived from the basic work of Clance (1985), Clance and Imes (1978), Harvey and Katz (1985), as well as Sakulku and Alexander (2011). After the definition of psychometric criteria and the exclusion of insufficient items, a questionnaire with 31 items containing six factors Competence Doubt, Working Style, Alienation, OtherSelf Divergence, Frugality and Need for Sympathy resulted. The predefined model requirements were valideted by confirmatory factor analysis. The indicator of internal consistency shows satisfactory reliability.

The investigation of the relationships between age and the IPP31 scales shows that age represents an important predictor for IP tendencies, except for the scale Frugality, which is positively related. Significant correlations between age and Competence Doubt $(r=-.21)$, Working-Style $(r=-.283)$, Other-Self Divergence $(r=-.13)$, Frugality $(r=.38)$ were found.

The psychometric properties of the questionnaire are sufficient, especially by considering Mcdonald's omega, which seems to be a more informative indicator regarding the low number of items. The goodness-of-fit indicators verify the quality of the questionnaire as sufficient.

The correlations of the IPP31 with other instruments might be an indicator for discriminatory validity. The total CIPS score, which is considered the most popular indicator for investigating the IP, showed a high correlation with the Competence Doubt scale. Also, Alienation and Other-Self Divergence showed high correlations with the total CIPS value. These correlations verify the construct validity of the IPP31. Interestingly, the total CIPS value, as well as the subscales Fake, Luck and Discount according to Brauer and Wolf (2016), showed no relation to the IPP31 scales Frugality and Need for Sympathy. This could be an indicator of a lack of construct-relatedness concerning these two IPP31 scales or the missing relation is an indicator of the CIPS deficits concerning the diagnostic representation of theoretical aspects.

Also, the strong association between Neuroticism and the IP (Bernard et al. 2002; Vergauwe et al. 2015) is shown by the correlation of Neuroticism with the scale Competence Doubt. In particular, the strong correlation between Competence Doubt and Depression signifies the convergent validity of the scale as well as the negative subjective quality of high Impostor tendencies. Interestingly, there is a medium-strong correlation between Neuroticism and Working Style. This is an indicator that people with greater tendencies to anxiety and depression also tend to procrastinate. The connections between Conscientiousness and Working Style as well as Competence Doubt verify the validity of the IPP31.
Besides, the Working Style scale allows individual assessment of the procrastination or precrastination tendency. Both working styles are typical for the IP but can be differentiated by scale values. As expected, Openness shows no connection to the Competence Doubt scale. The only scale of the IPP31 that shows a weak negative correlation to openness is Frugality. This correlation, however, seems to make sense since Openness is also called "intellect" (Digman 1990) and Frugality questions a careerist passivity. Research results on the relationship between CIPS and Extraversion (Chae et al. 1995; Ross et al. 2001) showed a weakly negative correlation. However, the scales Competence Doubt and Alienation show a medium negative correlation with Extraversion. This indicates that Competence Doubt does not fully correspond to the CIPS value. The high correlation to the scale Alienation and Competence Doubt in combination with the low correlation to Working Style and Need for Sympathy could be an indicator for the same measurement intention but at the same time higher differentiation between the IP elements by the IPP31.

The low correlations of the scales Frugality and Need for Sympathy with the dimension Agreeableness could be an indication that Agreeableness as a characteristic is not to be equated with the desire for subpersonal relationships. The facet Altruism of the scale Agreeableness showed the expected overlap with Need for Sympathy ( $9 \%$ shared variance), demonstrating the content validity of the scale.

The global Self-Esteem (RSES) showed strong negative correlations with the four scales Competence Doubt, Working Style, Alienation and Other-SelfDivergence and supports the convergent validity of the IPP31 scales.

Our findings support the hypotheses, except for the expected positive association between Frugality and Agreeableness. The link between Agreeableness and Frugality (H2f) was not as expected positive. Overall, the nomological validity of the IPP31 was largely supported.

\section{Limitations}

One point of criticism is the sample, which shows the biggest age segment in a range of 18 to 23 years and shows a rightskewed distribution. Especially considering that age is an important predictor of IP trends, as can be seen from the significant relationships to the four IPP31 scales. However, the age groups are sufficiently taken into account when both genders are considered together so that the results can be generalized for the German population. It should also be noted that the survey method was online-based so that the survey conditions could not be controlled, reducing the objectivity of execution. Also, the facet of perfectionism, which has a high weighting in the theoretical construct, was not assigned its scale within the 
questionnaire. The low eigenvalue of the scale Need for Sympathy [1.16] could also be an indicator of the low significance of the scale and should be evaluated concerning its practical relevance.

\section{Perspectives}

The construct validity of the Impostor-Profile could be supported by correlations with other constructs within the nomological network especially by strong correlations to the CIPS. In particular, the scale Competence Doubt shows substantial overlap with the CIPS. Interestingly, the scales Frugality and Need for Sympathy show no connections to CIPS. However, due to the proximity of the scales in terms of construct content described in the original literature (Table 4), they have a diagnostic value in the examination of Impostor tendencies. Given the lack of relationships with CIPS, these two scales, in particular, could provide incremental information gain. Another future research concern should be the construct validity, which must be checked in future studies using the HIPS, PFS, and LIS as well as further personality constructs. Moreover, future studies should examine criterion validity to check the practical relevance of the questionnaire.

Another possible step could be the factor-analytical extraction of a second-order factor. The factor loadings to the primary factors could serve as a weight, allowing the individual scale values to be weighted and added up to an ImpostorProfile total score. This score could be compared in further investigations with the total scores of HIPS, PFS, CIPS and LIS. Besides, a future research concern could be the determination of IPP31 cut-off equivalents to CIPS using ROC analysis (Receiver-Operating-Characteristics). This would allow measuring Impostor expressions according to the categorization of CIPS with the IPP31. The multidimensionality of the questionnaire would also make it possible to explore the presence of different types of Impostors by using cluster analysis and to check the theoretically formulated typology according to Harvey and Katz (1985).

This has so far been difficult due to the unidimensional instruments regarding IP. An impostor typology would, on the one hand, open up new research questions, and on the other hand, enable a type-appropriate development of interventions. Leonhardt et al. (2017) had identified a possible typological structure for the imposter phenomenon. Two types resulted, true impostors, which show negative selfperceptions and strategic impostors, which show a less negative attribution style. This typology could be validated by a cluster-analytical investigation of the IPP31 characteristics.

Furthermore, it would be useful to investigate the validity and factor structure for the English translation of the IPP31.

In conclusion, the resulting multidimensional questionnaire is psychometrically sufficient and theoretically based. Due to its profile character, the IPP31 can raise further research approaches regarding an impostor typology or help to clarify the construct's dimensionality. Besides, the questionnaire can gain practical relevance in coaching and therapeutic context. The multidimensionality enables higher resolved diagnostics and in consequence a more targeted intervention.

Funding Information Open Access funding provided by Projekt DEAL.

\section{Compliance with Ethical Standards}

Ethical Standards On behalf of all authors, the corresponding author states that there is no conflict of interest. The investigation has met the ethical standards for psychological investigations. No subject was negatively affected by participation.

\section{Appendix}

Table 4 Items of the IPP31 in the original German Version and an Tentative English Translation

\begin{tabular}{|c|c|c|}
\hline & Deutsch & English \\
\hline & Kompetenz-Zweifel & Competence Doubt \\
\hline 1 & Trotz vergangener Erfolge habe ich starke Versagensängste & Despite former successes, I have strong fear of failure \\
\hline 2 & Ich denke häufig, dass meine Fähigkeiten nicht ausreichen & I often think that my skills are not enough \\
\hline 3 & Prüfungssituationen sind für mich sehr belastend & Exam situations are very stressful for me \\
\hline 4 & Aus Angst zu versagen, verliere ich öfter den $\mathrm{Spa} ß$ an der Arbeit & My fear of failure often spoils the fun at work \\
\hline 5 & Ich bin von meinen Fähigkeiten nicht überzeugt & I am not convinced of my capabilities \\
\hline $6^{\mathrm{r}}$ & Ein Misserfolg ist kein Grund für mich, an meinen Fähigkeiten zu zweifeln & Failure is no reason for me to doubt my capabilities \\
\hline 7 & Ich bin meistens unzufrieden mit meinen Arbeitsleistungen & I am usually unsatisfied with my work \\
\hline 8 & Sehr gute Resultate Anderer verunsichern mich & When others get good results, it makes me insecure \\
\hline 9 & Ich habe Angst zu scheitern, obwohl ich meistens erfolgreich bin & I'm afraid to fail, even though I'm usually successful \\
\hline 10 & $\begin{array}{l}\text { Wenn ich erfolgreich bin, habe ich häufig das Gefühl, dass ein Misserfolg folgen } \\
\text { wird }\end{array}$ & When I am successful, I often feel that a failure will follow \\
\hline 11 & Mich belasten die hohen Erwartungen Anderer an mich & High expectations of others bother me \\
\hline
\end{tabular}


Table 4 (continued)

Deutsch

\section{Arbeitsstil}

12 Ich erschwere mir vieles, weil ich meine Arbeit aufschiebe

13 Oft verschiebe ich das Beginnen wichtiger Aufgaben

$14^{\mathrm{r}}$ Ich fange meine Aufgaben früher an als Andere

15 Ich beende wichtige Aufgaben meistens im letzten Moment

16 Ich lenke mich häufig ab, auch wenn ich viel zu erledigen habe

$17^{\mathrm{r}}$ Ich erledige die wichtigste Aufgabe meistens als erstes

\section{Entfremdung}

18 Oft verhalte ich mich unecht

19 Ich fühle mich oft so, als halte ich meine wirkliche Persönlichkeit zurück

20 Wirklich ich selbst bin ich nur selten

\section{Fremd-Selbst Divergenz}

21 Meine Fähigkeiten werden häufig überschätzt

22 Die Erwartungen meiner Kollegen an mich sind zu hoch

23 Man überschätzt mich

24 Ich werde häufig für klüger gehalten, als ich bin

\section{Genügsamkeit}

$25^{\mathrm{r}}$ Mir ist es sehr wichtig etwas Bedeutendes zu schaffen

$26^{\mathrm{r}}$ Eine Arbeit, bei der ich viele Untergebene hätte, würde mich befriedigen

$27^{\mathrm{r}}$ Bedeutendes zu leisten ist mir im Leben am wichtigsten

28 Ich wäre ungern Chef

\section{Sympathiebedürfnis}

29 Mir ist es wichtig sympatisch zu erscheinen

30 Mir ist es wichtig gemocht zu werden

31 Ich gelte als sehr hilfsbereite Person
English

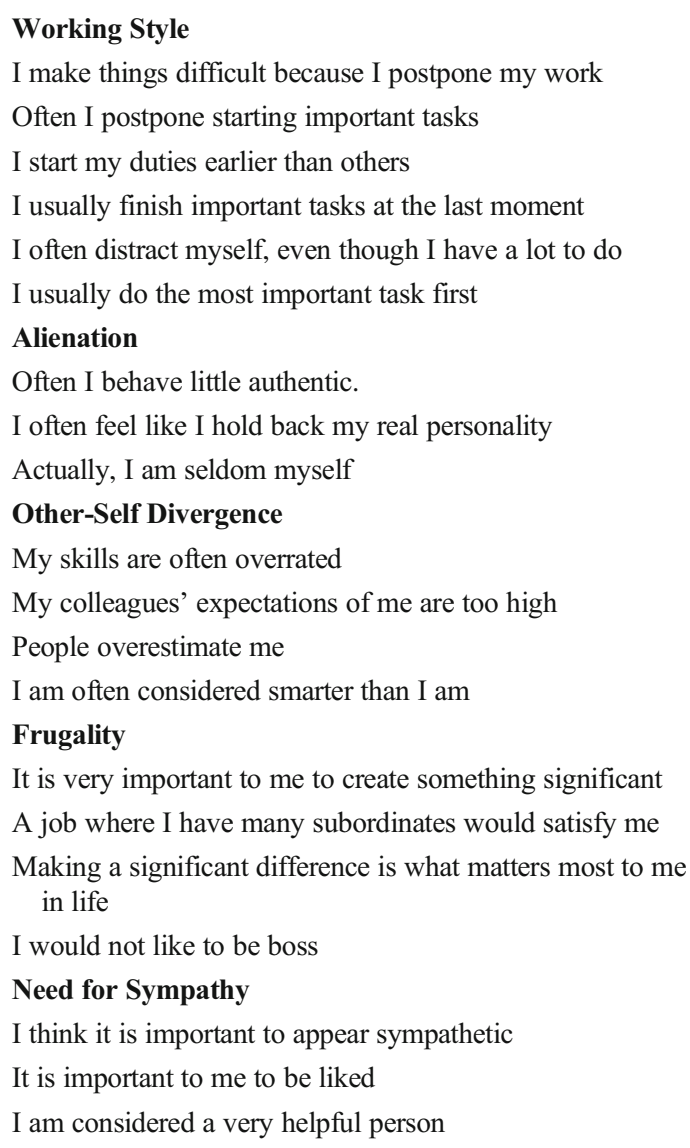

Original questionnaire in German; Translation without psychometric analysis; $r$ reversed item; a print version as well as a link to an interactive online version of the questionnaire can be found in the online Res1ource 1

Open Access This article is licensed under a Creative Commons Attribution 4.0 International License, which permits use, sharing, adaptation, distribution and reproduction in any medium or format, as long as you give appropriate credit to the original author(s) and the source, provide a link to the Creative Commons licence, and indicate if changes were made. The images or other third party material in this article are included in the article's Creative Commons licence, unless indicated otherwise in a credit line to the material. If material is not included in the article's Creative Commons licence and your intended use is not permitted by statutory regulation or exceeds the permitted use, you will need to obtain permission directly from the copyright holder. To view a copy of this licence, visit http://creativecommons.org/licenses/by/4.0/.

\section{References}

Badawy, R., Gazdag, B. A., Bentley, J., \& Brouer, R. (2017). I can’t fail if I don't try! A look into why impostors' self-handicap. Academy of Management Proceedings, 2017, 17349. https://doi.org/10.5465/ AMBPP.2017.17349abstract.

Bernard, N. S., Dollinger, S. J., \& Ramaniah, N. V. (2002). Applying the big five personality factors to the impostor phenomenon. Journal of
Personality Assessment, 78(2), 321-333. https://doi.org/10.1207/ S15327752JPA7802 07.

Brauer, K., \& Wolf, A. (2016). Validation of the German-language Clance impostor phenomenon scale (GCIPS). Personality and Individual Differences, 102, 153-158. https://doi.org/10.1016/j. paid.2016.06.071.

Chae, J.-H., Piedmont, R. L., Estadt, B. K., \& Wicks, R. J. (1995). Personological evaluation of Clance's imposter phenomenon scale in a Korean sample. Journal of Personality Assessment, 65(3), 468 485. https://doi.org/10.1207/s15327752jpa6503_7.

Chrisman, S. M., Pieper, W. A., Clance, P. R., Holland, C. L., \& Glickauf-Hughes, C. (1995). Validation of the Clance imposter phenomenon scale. Journal of Personality Assessment, 65, 456-467. https://doi.org/10.1207/s15327752jpa6503 6.

Clance, P. R., \& Imes, S. A. (1978). The imposter phenomenon in high achieving women: Dynamics and therapeutic intervention. Psychotherapy: Theory, Research \& Practice, 15(3), 241-247. https://doi.org/10.1037/h0086006.

Clance, P. R. (1985). Erfolgreiche Versager. das HochstaplerPhänomen. München: Heyne.

Clance, P. R., \& O'Toole, M. A. (1988). The imposter phenomenon: An internal barrier to empowerment and achievement. Women \& Therapy, 6, 51-64. https://doi.org/10.1300/J015V06N03_05. 
Digman, J. M. (1990). Personality structure: Emergence of the five-factor model. Annual Review of Psychology, 41(1), 417-440.

Edwards, P. W., Zeichner, A., Lawler, N., \& Kowalski, R. (1987). A validation study of the Harvey impostor phenomenon scale. Psychotherapy: Theory, Research, Practice, Training, 24(2), 256.

Ferrari, J. R., \& Thompson, T. (2006). Impostor fears: Links with selfpresentational concerns and self-handicapping behaviours. Personality and Individual Differences, 40, 341-352. https://doi. org/10.1016/j.paid.2005.07.012.

French, B. F., Ullrich-French, S. C., \& Follman, D. (2008). The psychometric properties of the Clance impostor scale. Personality and Individual Differences, 44, 1270-1278. https://doi.org/10.1016/j. paid.2007.11.023.

Fried-Buchalter, S. (1997). Fear of success, fear of failure, and the imposter phenomenon among male and female marketing managers. Sex Roles, 37(11-12), 847-859. https://doi.org/10.1007/ BF02936343.

Fujie, R. (2010). Development of the state impostor phenomenon scale. Japanese Psychological Research, 52(1), 1-11. https://doi.org/10. 1111/j.1468-5884.2009.00417.x.

Gravois, J. (2007). You're not fooling anyone. The Chronicle of Higher Education, 54(11), A1 Retrieved November 5, 2008, from http:// chronicle.com.

Harvey, J. C. (1981). The impostor phenomenon and achievement: A failure to internalize suc-cess (unpublished doctoral dissertation). Philadelphia: Temple University.

Harvey, J., \& Katz, C. (1985). Das Hochstapler-Phänomen: Die Angst vor dem Erfolg ; Ursachen, Auswirkung, Überwindung. Landsberg am Lech: mvg-Verlag.

Hellman, C. M., \& Caselman, T. D. (2004). A psychometric evaluation of the Harvey imposter phenomenon scale. Journal of Personality Assessment, 83(2), 161-166. https://doi.org/10.1207/ s15327752jpa8302_10.

Henning, K., Ey, S., \& Shaw, D. (1998). Perfectionism, the impostor phenomenon and psychological adjustment in medical, dental, nursing and pharmacy students. Medical Education, 32(5), 456-464. https://doi.org/10.1046/j.1365-2923.1998.00234.x.

Holmes, S. W., Kertay, L., Adamson, L. B., Holland, C. L., \& Clance, P. R. (1993). Measuring the impostor phenomenon: A comparison of Clance's IP scale and Harvey's IP scale. Journal of Personality Assessment, 60(1), 48-59. https://doi.org/10.1207/ s15327752jpa6001_3.

Horn, J. L. (1965). A rationale and test for the number of factors in factor analysis. Psychometrika, 30, 179-185. https://doi.org/10.1007/ BF02289447.

Hutchins, H. M. (2015). Outing the imposter: A study exploring imposter phenomenon among higher education faculty. New Horizons in Adult Education and Human Resource Development, 27(2), 3-12. https://doi.org/10.1002/nha3.20098.

Hu, L. T., \& Bentler, P. M. (1999). Cutoff criteria for fit indexes in covariance structure analysis: Conventional criteria versus new alternatives. Structural Equation Modeling: A Multidisciplinary Journal, 6(1), 1-55.

Jöstl, G., Bergsmann, E., Lüftenegger, M., Schober, B., \& Spiel, C. (2012). When will they blow my cover? Zeitschrift für Psychologie, 220, 109-120. https://doi.org/10.1027/2151-2604/ a000102.

Kolligian Jr., J., \& Sternberg, R. J. (1991). Perceived fraudulence in young adults: Is there an'Imposter syndrome'? Journal of Personality Assessment, 56(2), 308-326. https://doi.org/10.1207/ s15327752jpa5602_10.

Kuhlmann, T., Dantlgraber, M., \& Reips, U.-D. (2017). Investigating measurement equivalence of visual analogue scales and Likerttype scales in internet-based personality questionnaires. Behavior Research Methods, 49(6), 2173-2181. https://doi.org/10.3758/ s13428-016-0850-x.
Kumar, S., \& Jagacinski, C. M. (2006). Imposters have goals too: The imposter phenomenon and its relationship to achievement goal theory. Personality and Individual Differences, 40(1), 147-157. https:// doi.org/10.1016/j.paid.2005.05.014.

Leach, P. K., Nygaard, R. M., Chipman, J. G., Brunsvold, M. E., \& Marek, A. P. (2019). Impostor phenomenon and burnout in general surgeons and general surgery residents. Journal of Surgical Education, 76(1), 99-106. https://doi.org/10.1016/j.jsurg.2018.06. 025 .

Leary, M. R., Patton, K. M., Orlando, A. E., \& Wagoner Funk, W. (2000). The impostor phenomenon: Self-perceptions, reflected appraisals, and interpersonal strategies. Journal of Personality, 68(4), 725-756. https://doi.org/10.1111/1467-6494.00114.

Leonhardt, M., Bechtoldt, M. N., \& Rohrmann, S. (2017). All impostors aren't alike-differentiating the impostor phenomenon. Frontiers in Psychology, 8, 1505.

Lester, D., \& Moderski, T. (1995). The impostor phenomenon in adolescents. Psychological Reports, 76(2), 466-466. https://doi.org/10. 2466/pr0.1995.76.2.466.

Mak, K. K. L., Kleitman, S., \& Abbott, M. J. (2019). Impostor phenomenon measurement scales: A systematic review. Frontiers in Psychology, 10, 671. https://doi.org/10.3389/fpsyg.2019.00671.

Matthews, G., \& Clance, P. R. (1985). Treatment of the impostor phenomenon in psychotherapy clients. Psychotherapy in Private Practice, 3(1), 71-81. https://doi.org/10.1300/J294v03n01_09.

Parkman, A. (2016). The imposter phenomenon in higher education: Incidence and impact. Journal of Higher Education Theory and Practice, 16(1), 51.

Prince, T. J. (1989). The impostor phenomenon revisited: A validity study of Clance's IP Scale (PhD Thesis). Georgia State University.

Rammstedt, B. (1997). Die deutsche Version des Big Five Inventory (BFI): Übersetzung und Validierung eines Fragebogens zur Erfassung des Fünf-Faktoren-Modells der Persönlichkeit (Doctoral dissertation, publisher not determinable).

Rammstedt, B., \& Danner, D. (2016). Die Facettenstruktur des big five inventory (BFI): Validierung für die deutsche adaptation des BFI [The facet structure of the big five inventory (BFI): Validation for the German adaptation of the BFI]. Diagnostica, 63, 70-84. https:// doi.org/10.1026/0012-1924/a000161.

Reips, U.-D., \& Funke, F. (2008). Interval-level measurement with visual analogue scales in internet-based research: VAS generator. Behavior Research Methods, 40(3), 699-704.

Revelle, W., \& Revelle, M. W. (2015). Package 'psych'. The Comprehensive R Archive Network.

Revelle, W., \& Zinbarg, R. E. (2009). Coefficients alpha, Beta, omega, and the glb: Comments on Sijtsma. Psychometrika, 74(1), 145-154. https://oi.org/10.1007/s11336-008-9102-z.

Rhemtulla, M., Brosseau-Liard, P. É., \& Savalei, V. (2012). When can categorical variables be treated as continuous? A comparison of robust continuous and categorical SEM estimation methods under suboptimal conditions. Psychological Methods, 17(3), 354-373. https://doi.org/10.1037/a0029315.

Rogan, J. (2019). (Joe Rogan; Jamie Vernon) The Joe Rogan Experience. In JRE \#1365 - CAMERON HANES. Abgerufen von http://podcasts. joerogan.net/podcasts/cameron-hanes- 9

Rohrmann, S., Bechtoldt, M. N., \& Leonhardt, M. (2016). Validation of the impostor phenomenon among managers. Frontiers in Psychology, 7. https://doi.org/10.3389/fpsyg.2016.00821.

Rosenberg, M. (1965). Society and the adolescent self-image. Princeton: Princeton University Press.

Ross, S. R., Stewart, J., Mugge, M., \& Fultz, B. (2001). The imposter phenomenon, achievement dispositions, and the Five Factor Model. Personality and Individual Differences, 31(8), 1347-1355.

Rosseel, Y., Oberski, D., Byrnes, J., Vanbrabant, L., Savalei, V., Merkle, E., Hallquist, M., Rhemtulla, M., Katsikatsou, M., \& Barendse, M [Mariska]. (2017). Package 'lavaan'. 
Sakulku, J., \& Alexander, J. (2011). The impostor phenomenon. International Journal of Behavioral Science, 6, 73-92.

Sanford, A. A., Ross, E. M. R. M., Blake, S. J., \& Cambiano, R. L. (2015). Finding courage and confirmation: Resisting impostor feelings through relationships with mentors, romantic partners, and other women in leadership. Advancing Women in Leadership Journal, $35,31-41$.

Schubert, N., \& Bowker, A. (2017). Examining the impostor phenomenon in relation to self-esteem level and self-esteem instability. Current Psychology, 38(3), 749-755. https://doi.org/10.1007/ s12144-017-9650-4.

Sightler, K. W., \& Wilson, M. G. (2001). Correlates of the impostor phenomenon among undergraduate entrepreneurs. Psychological Reports, 88(3), 679-689. https://doi.org/10.2466/pr0.2001.88.3. 679.

Simon, M., \& Choi, Y.-J. (2018). Using factor analysis to validate the Clance impostor phenomenon scale in sample of science, technology, engineering and mathematics doctoral students. Personality and Individual Differences, 121, 173-175. https://doi.org/10.1016/j. paid.2017.09.039.

Thompson, T., Davis, H., \& Davidson, J. (1998). Attributional and affective responses of impostors to academic success and failure outcomes. Personality and Individual Differences, 25(2), 381-396. https://doi.org/10.1016/S0191-8869(98)00065-8.

Thompson, T., Foreman, P., \& Martin, F. (2000). Impostor fears and perfectionistic concern over mistakes. Personality and Individual
Differences, 29(4), 629-647. https://doi.org/10.1016/S01918869(99)00218-4.

Vergauwe, J., Wille, B., Feys, M., De Fruyt, F., \& Anseel, F. (2015). Fear of being exposed: The trait-relatedness of the impostor phenomenon and its relevance in the work context. Journal of Business and Psychology, 30(3), 565-581. https://doi.org/10.1007/s10869-0149382-5.

Von Collani, G., \& Herzberg, P. Y. (2003). Zur internen Struktur des globalen Selbstwertgefühls nach Rosenberg [On the Internal Structure of Global Self-Esteem (Rosenberg)]. Zeitschrift für Differentielle und Diagnostische Psychologie, 24(1), 9-22. https:// doi.org/10.1024//0170-1789.24.1.9.

Want, J., \& Kleitman, S. (2006). Imposter phenomenon and selfhandicapping: Links with parenting styles and self-confidence. Personality and Individual Differences, 40(5), 961-971. https:// doi.org/10.1016/j.paid.2005.10.005.

Ziegler, M., Kemper, C. J., \& Kruyen, P. (2014). Short scales - Five misunderstandings and ways to overcome them. Journal of Individual Differences, 35(4), 185-189. https://doi.org/10.1027/ 1614-0001/a000148.

Publisher's Note Springer Nature remains neutral with regard to jurisdictional claims in published maps and institutional affiliations. 